\title{
Clinical Epidemiology of Cardiovascular Disease in Chronic Kidney Disease
}

\author{
K. Kundhal C.E. Lok \\ University Health Network-Toronto General Hospital, University of Toronto, Toronto, Canada
}

\section{Key Words}

Cardiovascular disease $\cdot$ Chronic kidney disease •

\begin{abstract}
Cardiovascular disease (CVD) is the most common cause of death in patients with chronic kidney disease (CKD) and end-stage renal disease (ESRD). The clinical epidemiology of CVD in CKD is challenging due to a prior lack of standardized definitions of CKD, inconsistent measures of renal function, and possible alternative effects of 'traditional' CVD risk factors in patients with CKD. These challenges add to the complexity of the role of renal impairment as the cause or the consequence of cardiovascular disease. The goal of this review is to summarize the current evidence on: (1) the incidence and prevalence of CVD in chronic renal insufficiency and in ESRD, (2) risk factors for CVD in CKD, (3) the outcomes of patients with renal failure with CVD, and (4) CKD as a risk factor for CVD. The epidemiological associations implicating the huge burden of CVD throughout all stages of CKD highlight the need to better understand and implement adequate screening, and diagnostic and treatment strategies.
\end{abstract}

Copyright $(C 2005$ S. Karger AG, Basel
Reduced renal function has been estimated to affect almost 1 in 5 people in North America [1, 2]. Furthermore, renal impairment is associated with significant comorbidity that increases with progressive renal decline. Once an individual reaches end-stage renal disease (ESRD), cardiovascular disease (CVD) is responsible for approximately half of deaths. These individuals are 20 times more likely to have a cardiovascular-related death than for their kidneys to progressively fail to require dialysis or transplantation.

The clinical epidemiology of CVD in chronic kidney disease (CKD) is challenging due to a prior lack of standardized definitions of CKD and problems with the consistency of estimates of renal function. Another challenge has been 'reverse epidemiology' where the effects of 'traditional' CVD risk factors are different from those in the general population. In light of these challenges, the goal of this review is to summarize the current evidence on: (1) the incidence and prevalence of CVD in chronic renal insufficiency, (2) the incidence and prevalence of CVD in ESRD, (3) risk factors for CVD in CKD, (4) the outcomes of patients with renal failure with CVD, and (5) CKD as a risk factor for CVD. In this review, CKD is defined using NKF-DOQI guidelines and CVD encompasses coronary artery disease (CAD), cerebrovascular disease (CBVD), peripheral vascular disease (PVD), congestive heart failure $(\mathrm{CHF})$, and left ventricular hypertrophy (LVH).
Dr. Charmaine Lok

University Health Network-Toronto General Hospital

11EN216, 200 Elizabeth St.

Toronto M5G 2 C4 (Canada)

Tel. +1 416340 4140, Fax +1 416586 9827, E-Mail charmaine.lok@uhn.on.ca 


\section{The Incidence and Prevalence of CVD in CKD (NKF-DOQI CKD Stages 1-4)}

\section{Incidence}

Only one prospective study has determined the incidence of CVD in a non-ESRD cohort without CVD at baseline. Jungers et al. [3] followed 147 patients for 10 years and found an incidence of CVD events (myocardial infarction, ischemic stroke) of $41 \%$ in men and 19\% in women. The incidence of myocardial infarction was three times higher in men with CKD than in the general male population in all age groups. The same was true for women until age 65 years, after which the difference became less marked. The mean GFR was $31 \mathrm{ml} / \mathrm{min}$ at the time of the events. In a prospective cohort of non-ESRD patients that included CHF as part of its CVD outcomes, Levin et al. [4] found, in a patient subset, that $7.4 \%$ with no previous CVD developed new cardiac disease. This is consistent with a recent population study of approximately 16,000 patients (ARIC study) where the incidence of de novo cardiovascular events was 4.8\% ( 8.3 events/ 1,000 person-years) if the patient was in stage 2 CKD and 9.3\% $(16.8 / 1,000$ person years) if in stage $3-4$ CKD [5].

In a study of 6,223 people in the Framingham study, $18 \%$ of men and $20 \%$ of women with renal impairment already had CVD [6]. The incidence rate of cardiovascular events (CAD, CHF, ischemic stroke) was 21.3/1,000 patient-years for men and 25.6/1,000 patient-years for women with stage $3 \mathrm{CKD}$. This contrasts with 18.5 and 11.0 per 1,000 patient-years in men and women, respectively, with a lower serum creatinine (SCr).

In a Canadian cohort of pre-ESRD patients with known baseline CVD, who were followed for a median of 23 months, 35\% developed a new event, worsening CVD, or were hospitalized for cardiac disease [4]. In the ARIC study, the incidence of recurrent events over a mean duration of 6.2 years was $20.4 \%$ (38.1 events $/ 1,000$ person years; stage 2 CKD) and $28.4 \%(60.8 / 1,000$ person years; stage 3-4 CKD) [5].

\section{Prevalence}

The Framingham Heart Study found the prevalence of CVD in people with renal impairment (SCr 136-265 $\mu \mathrm{mol} / \mathrm{l}$ in men and $120-265 \mu \mathrm{mol} / \mathrm{l}$ in women) to be $64 \%$ higher compared with individuals with lower SCr values [6]. A recent population-based study of 1.12 million people found a prevalence in patients with GFR $<60 \mathrm{ml} / \mathrm{min}$ (CKD stage 3 or less) of $14.9 \%$ with CAD, $6.8 \%$ CBVD, $5.0 \%$ PVD and $7.1 \%$ with CHF [2]. In a Canadian multicenter prospective cohort of 313 pre-ESRD patients, the prevalence of all CVD was 38\% [4]. The prevalence of $\mathrm{LVH}$ has been found to increase with a decline in renal function. Indeed, large population-based studies consistently find a high prevalence of CVD [7]. Conversely, in a study of 14,527 people with known CAD (diagnosed myocardial infarction) $33.6 \%$ had stage 3 or greater CKD [8].

\section{Incidence and Prevalence of CVD in ESRD}

\section{Incidence}

The incidence of CVD in the ESRD population is strikingly high. Over a 2.2-year follow-up, a USA prospective study (Wave2 substudy of the DMMS) of 4,204 patients initiating dialysis during 1996 and 1997 found the incidence of acute coronary syndromes, CHF, stroke, and PVD to be 10.2, 13.6, 2.2, and 14\%, respectively [9]. Even amongst renal transplant recipients, the incidence of CVD is 3-4 times that observed in age-matched controls [10].

\section{Prevalence}

The prevalence of CHF, CAD and stroke is 1.8-, 3.2-, and 4.6-fold greater than its incidence in people with ESRD [9]. Of patients initiating dialysis, only $15 \%$ had normal left-ventricular (LV) structure and function by echocardiography [11]. Foley et al. [11] have documented a prevalence of $\mathrm{LVH}$ of $74 \%$ in this population - almost 2 -fold greater than the $38 \%$ prevalence found in a study of pre-ESRD patients [7]. From large databases of patients with ESRD, the prevalence of CAD, CHF, CBVD, and PVD are $36,39,13$, and $22 \%$, respectively [12]. The large discrepancy between the incidence of CVD and its prevalence in this population suggests that we can intervene to delay or prevent CVD. The challenge is to identify the truly significant risk factors that play a role in the development of CVD, in order to determine and apply appropriate interventions.

\section{Risk Factors for CVD in CKD}

Established 'traditional' atherosclerotic risk factors, such as diabetes, hypertension, dyslipidemia, and older age, have been found to be independent predictors of CVD in CKD. In addition, hemodynamic and metabolic factors such as volume overload, anemia, calcium and phosphorus imbalance, chronic inflammation, and a hypercoagulable milieu are unique features of renal insuf- 
ficiency that may contribute to the risk and pathogenesis of CVD. In renal transplant patients, factors such as source of donation, graft failure, and type of immunosuppressive therapy may play a role.

Several of the traditional risk factors in the general population demonstrate a phenomenon known as 'reverse epidemiology' in the CKD population. For example, obesity and hypertension are established CVD risk factors in the general population, whereas lower body mass index [13] and hypotension [14] have been shown to be risk factors for cardiovascular mortality in ESRD. To date, there has only been one prospective observational study of dialysis patients that controlled for baseline cardiac function [15]. Foley et al. [15]. found that a $10 \mathrm{~mm} \mathrm{Hg}$ mean blood pressure increase was associated with a $44 \%$ higher risk of developing $\mathrm{CHF}$ and that patients with chronic CHF or LVH are at higher risk of mortality compared with patients without these cardiac abnormalities.

\section{Outcomes}

In 1997, the death rate from CVD (excluding CBVD) was approximately 22 times that from renal disease in the general population [16]. A proportion of $40 \%$ of individuals with CKD will have a CVD-related death.

\section{Mortality: Stages 1-4}

The proportion of patients that will die due to cardiovascular disease is at least three times greater than that of patients who will die of renal disease. For example, in a randomized, multicenter prevention trial of 347,978 high-risk men with no CVD at baseline ( $\mathrm{SCr}$ $<177 \mu \mathrm{mol} / \mathrm{l}$ ) the crude rate of death from CAD was 23 times greater in blacks and 88 times greater in Caucasians than the death rate from renal disease [17]. Individuals with established CVD have 3 times the CVD events and all-cause mortality compared with those without baseline CVD [18].

\section{Mortality: Stage 5}

The risk of cardiac events in patients who are dependent on dialysis or a kidney transplant is estimated to be between 3.5 and 50 times higher than in the general population. The annual mortality on dialysis is $20-23 \%$, with cardiovascular causes accounting for $45 \%$ of these deaths. Furthermore, the prognosis after acute myocardial infarction is poor. A recent, large population based study demonstrated 1- and 5-year mortality rates to be 59 and 90\%, respectively [19]: that is 16-19 times higher compared with the general population. Likewise, transplant patients who develop de novo CAD or CHF have a 1.5-2.0 higher risk of death than nonrenal patients [20]. Mortality after stroke is also increased [21]. For patients who undergo cardiac revascularization, the in-hospital, 30-day and 1 year mortality was worse with greater degrees of renal impairment in a 26,500-patient cohort with a wide range of CKD [22].

\section{Renal Impairment as a Risk Factor for CVD}

Is CKD an independent risk factor for CVD or is it simply a marker of underlying atherogenic pathology and CVD? Several large prospective studies have suggested that even mild degrees of renal impairment may be associated with cardiovascular disease and mortality (fig. 1, 2) [8, 23-34]. For example, within a large populationbased study (Hoorn) a decrease in glomerular filtration rate of $5 \mathrm{ml} / \mathrm{min} / 1.73 \mathrm{~m}^{2}$ was associated with a $22 \%$ increased risk of cardiovascular death after adjustment for traditional CV risk factors and previous CVD [31]. In a population-based study of 26,500 patients with known CAD awaiting CABG, patients with renal insufficiency (stage 3 or greater) had a greater prevalence of left main disease $(23.5 \%)$ compared with patients with creatinine clearance $>60 \mathrm{ml} / \mathrm{min}(17.5 \%)$ [22]. However, with the high underlying prevalence of CVD and with the knowledge that the severity of general atherosclerosis is highly correlated with the severity of glomerulosclerosis, renal impairment could simply be a surrogate marker for the presence and severity of risk factors and/or underlying arterio- or atherosclerosis.

The data examining whether or not renal impairment is an independent risk factor are conflicting. Even when adjustments are made for the severity of the coronary anatomy, the risk of future adverse events remain elevated in patients with renal insufficiency, suggesting that it may be an independent risk factor. A large populationbased study ( $>1.1$ million) demonstrated a graded independent increase in hazard of death from any cause, any cardiovascular event (hospitalization for CAD, CHF, CBVD, or PVD) or any hospitalization with progressively declining renal function [35]. This analysis adjusted for multiple covariates, including most traditional cardiovascular risk factors. A prior pooled analysis of four large community-based studies demonstrated that CKD is a risk factor for the composite outcome of all-cause mortality and cardiovascular disease in patients with stage 3 or $4 \mathrm{CKD}$ compared with individuals with a GFR $\geq 60 \mathrm{ml} /$ min [36]. However, renal function was not a risk factor 


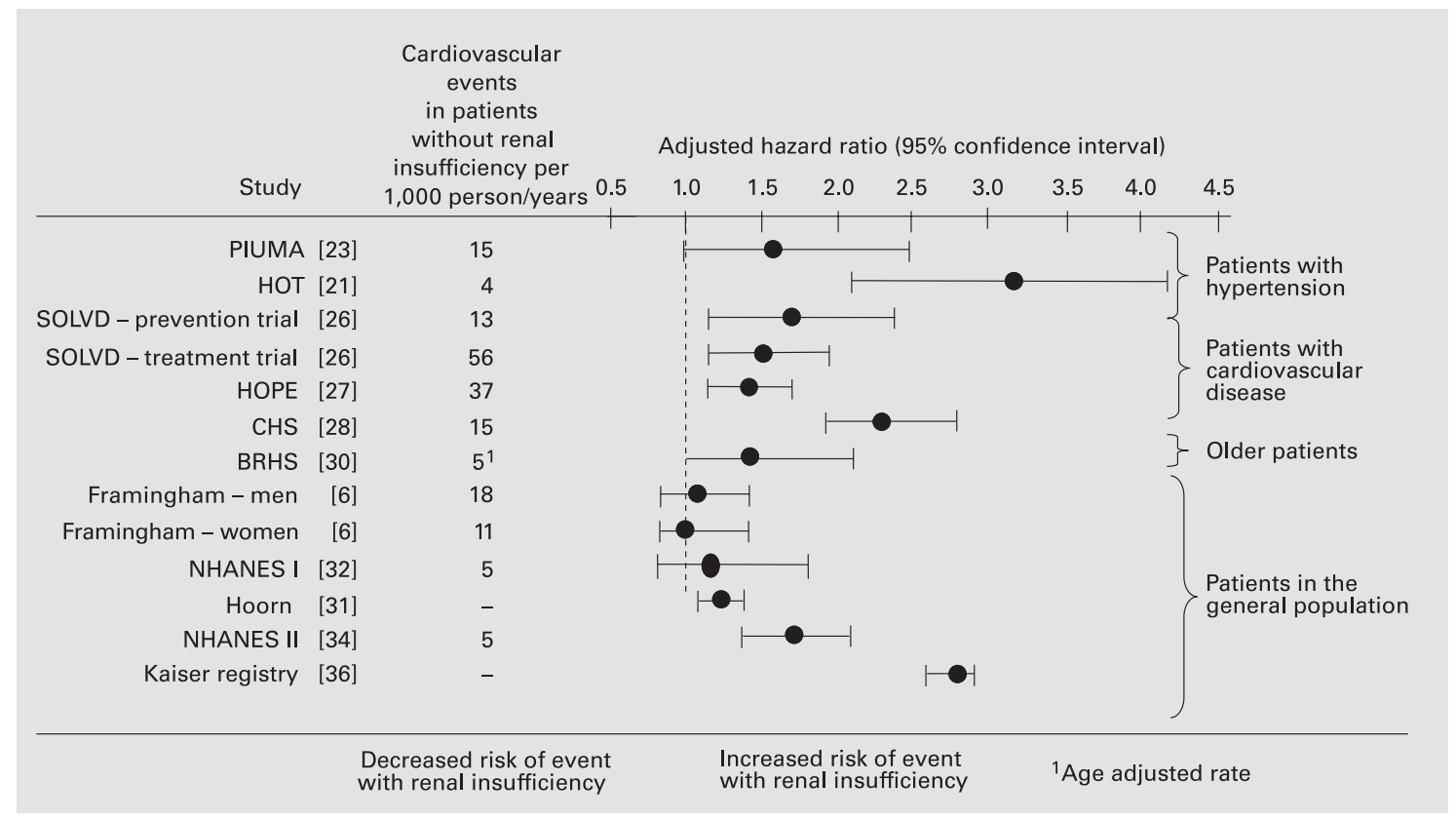

Fig. 1. Graphical presentation of the independent risk of renal insufficiency on cardiovascular events, adjusted for traditional cardiovascular risk factors. Comparing cardiovascular event rates was problematic as different cardiovascular outcomes were reported in studies. Cardiovascular events represent heart failure, myocardial infarction, stroke, associated mortalities or some composite of cardiovascular disease.

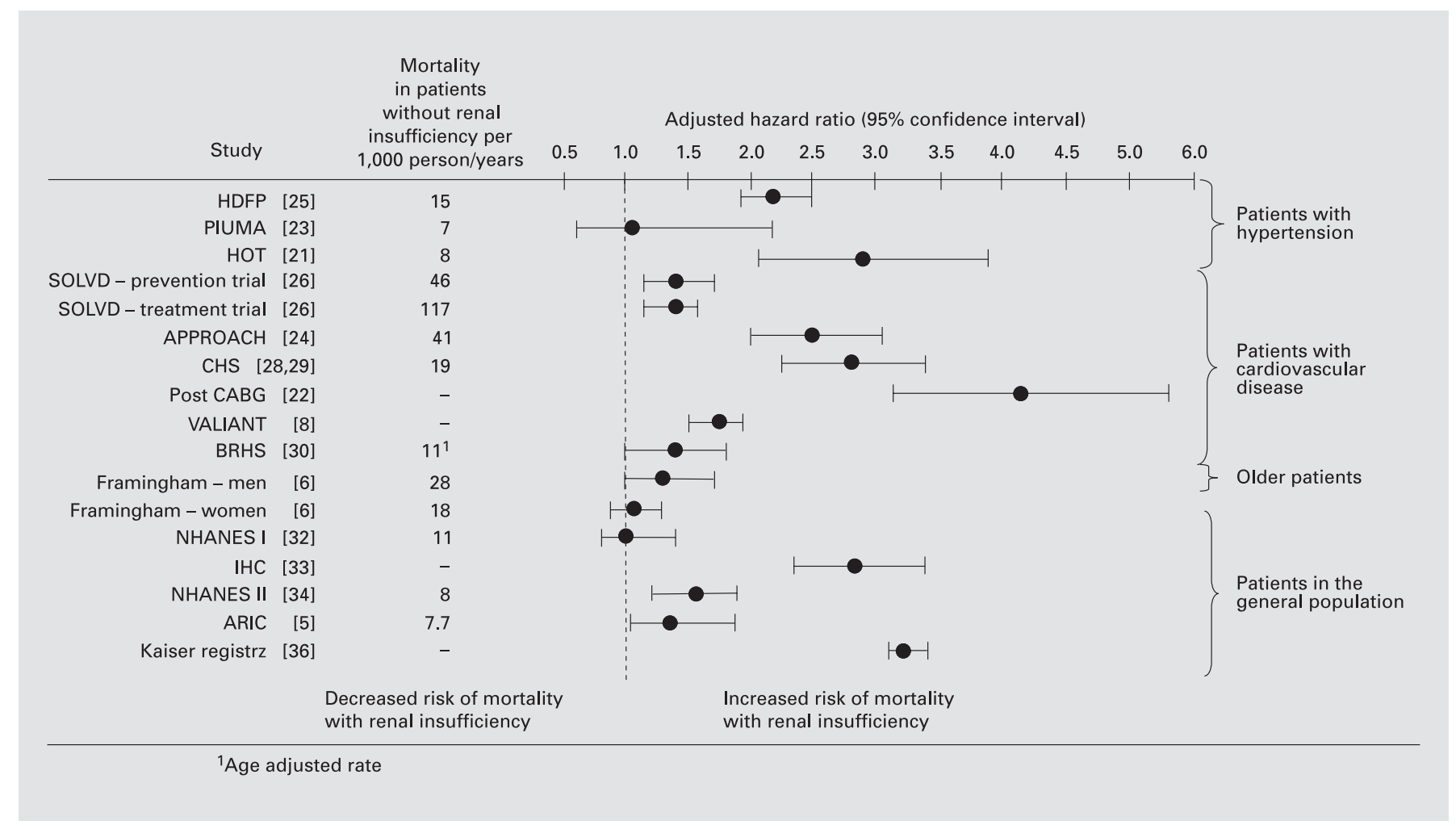

Fig. 2. The independent risk of renal insufficiency on total mortality, adjusted for traditional cardiovascular risk factors. 
for CAD or CBVD in their fully adjusted model. In other large population-based studies, including the Framingham and NHANES I studies, any univariate associations with mild or moderate renal insufficiency and cardiovascular or all-cause mortality lost significance when adjustments were made for traditional CVD risk factors [4, 21]. Some of the traditional CVD risk factors are also risk factors associated with a faster GFR decline. Therefore it is difficult to determine whether declining GFR is a risk factor for CVD due to its confounding effect. It is highly likely that there are significant undeclared risk factors that play a role in both CKD and CVD that are not fully accounted for by statistical analysis.

The question of whether CKD is independently associated with an increased risk for CVD, whether CVD causes
CKD, or whether some known or unknown factor(s) causes both, will continue to be hotly debated. However, to an extent, CKD is nonreversible. The key focus should be the early detection and prevention of progression of CKD at stages 1 and 2 using established and emerging therapies. Cardiovascular risk factor identification and management may depend on CKD staging. Special focus on non-traditional risk factors in CKD stages 3-5 may be appropriate in addition to traditional risk factor modification initiated in CKD stages 1 and 2. Lastly, there is a need to disseminate information to primary care providers who may be key players in initiating and maintaining the most appropriate management strategies. For those with established CVD and CKD that require intervention, the increased risks must be considered and addressed.

\section{References}

1 Clase CM GA, Kiberd BA: Estimating the prevalence of low glomerular filtration rate requires attention to the creatinine assay calibration. J Am Soc Nephrol 2002; 13:2811-2816.

$\checkmark 2$ Go AS, Chertow GM, Fan D, McCulloch CE, Hsu CY: Chronic kidney disease and the risks of death, cardiovascular events, and hospitalization (see comment). N Engl J Med 2004; 351:1296-1305.

-3 Jungers P, Massy ZA, Khoa TN, Fumeron C, Labrunie M, Lacour B, Descamps-Latscha B, Man NK: Incidence and risk factors of atherosclerotic cardiovascular accidents in predialysis chronic renal failure patients: a prospective study. Nephrol Dial Transplant 1997; 12: 2597-2602.

-4 Levin A, Djurdjev O, Barrett B, Burgess E, Carlisle E, Ethier J, Jindal K, Mendelssohn D, Tobe S, Singer J, Thompson C: Cardiovascular disease in patients with chronic kidney disease: Getting to the heart of the matter. Am J Kidney Dis 2001;38:1398-1407.

5 Manjunath G, Tighiouart H, Ibrahim H, MacLeod B, Salem DN, Griffith JL, Coresh J, Levey AS, Sarnak MJ: Level of kidney function as a risk factor for atherosclerotic cardiovascular outcomes in the community. J Am Coll Cardiol 2003;41:47-55.

6 Culleton BF, Larson MG, Wilson PW, Evans JC, Parfrey PS, Levy D: Cardiovascular disease and mortality in a community-based cohort with mild renal insufficiency. Kidney Int 1999;56:2214-2219.

7 Levin A, Singer J, Thompson CR, Ross H, Lewis M: Prevalent left ventricular hypertrophy in the predialysis population: Identifying opportunities for intervention. Am J Kidney Dis 1996;27:347-354.
-8 Anavekar NS, McMurray JJ, Velazquez EJ, Solomon SD, Kober L, Rouleau JL, White HD, Nordlander R, Maggioni A, Dickstein K, Zelenkofske S, Leimberger JD, Califf RM, Pfeffer MA: Relation between renal dysfunction and cardiovascular outcomes after myocardial infarction [see comment]. $\mathrm{N}$ Engl J Med 2004;351:1285-1295.

$\checkmark 9$ Foley RN, Herzog CA, Collins AJ: Smoking and cardiovascular outcomes in dialysis patients: The United States Renal Data System Wave 2 Study. Kidney Int 2003;63:14621467.

10 Kasiske BL: Risk factors for accelerated atherosclerosis in renal transplant recipients. Am J Med 1988;84:985-992.

11 Foley RN, Parfrey PS, Harnett JD, Kent GM, Martin CJ, Murray DC, Barre PE: Clinical and echocardiographic disease in patients starting end-stage renal disease therapy. Kidney Int 1995;47:186-192.

12 Foley RN, Herzog CA, Collins AJ: Blood pressure and long-term mortality in United States hemodialysis patients: USRDS Waves 3 and 4 Study. Kidney Int 2002;62:1784-1790.

13 Kopple JD, Zhu X, Lew NL, Lowrie EG: Body weight-for-height relationships predict mortality in maintenance hemodialysis patients. Kidney Int 1999;56:1136-1148.

14 Zager PG, Nikolic J, Brown RH, Campbell MA, Hunt WC, Peterson D, Van Stone J, Levey A, Meyer KB, Klag MJ, Johnson HK, Clark E, Sadler JH, Teredesai P: 'U' curve association of blood pressure and mortality in hemodialysis patients. Medical Directors of Dialysis Clinic, Inc. Kidney Int 1998;54:561569.
15 Foley RN, Parfrey PS, Harnett JD, Kent GM, Murray DC, Barre PE: Impact of hypertension on cardiomyopathy, morbidity and mortality in end-stage renal disease. Kidney Int 1996;49: 1379-1385.

16 Canada S: http://www.statcan.ca/english/ Pgdb/health36.htm, 2003

$>17$ Flack JM, Neaton JD, Daniels B, Esunge P: Ethnicity and renal disease: Lessons from the Multiple Risk Factor Intervention Trial and the Treatment of Mild Hypertension Study. Am J Kidney Dis 1993;21:31-40.

18 Manjunath G, Tighiouart H, Coresh J, Macleod B, Salem DN, Griffith JL, Levey AS, Sarnak MJ: Level of kidney function as a risk factor for cardiovascular outcomes in the elderly. Kidney Int 2003;63:1121-1129.

19 Herzog CA, Ma JZ, Collins AJ: Poor long-term survival after acute myocardial infarction among patients on long-term dialysis. N Engl J Med 1998;339:799-805.

20 Rigatto C: Clinical epidemiology of cardiac disease in renal transplant recipients. Semin Dial 2003;16:106-110.

-21 Ruilope LM, Salvetti A, Jamerson K, Hansson L, Warnold I, Wedel H, Zanchetti A: Renal function and intensive lowering of blood pressure in hypertensive participants of the hypertension optimal treatment (HOT) study. J Am Soc Nephrol 2001;12:218-225.

22 Lok CE, Austin PC, Wang H, Tu JV: Impact of renal insufficiency on short- and long-term outcomes after cardiac surgery. Am Heart J 2004; 148:430-438.

23 Schillaci G, Reboldi G, Verdecchia P: Highnormal serum creatinine concentration is a predictor of cardiovascular risk in essential hypertension. Arch Intern Med 2001;161:886891 
-24 Hemmelgarn BR, Ghali WA, Quan H, Brant R, Norris CM, Taub KJ, Knudtson ML: Poor long-term survival after coronary angiography in patients with renal insufficiency (see comment). Am J Kidney Dis 2001;37:64-72.

25 Shulman NB, Ford CE, Hall WD, Blaufox MD Simon D, Langford HG, Schneider KA: Prognostic value of serum creatinine and effect of treatment of hypertension on renal function. Results from the hypertension detection and follow-up program. The Hypertension Detection and Follow-up Program Cooperative Group. Hypertension 1989;13:I80-I93.

-26 Dries DL, Exner DV, Domanski MJ, Greenberg B, Stevenson LW: The prognostic implications of renal insufficiency in asymptomatic and symptomatic patients with left ventricular systolic dysfunction. J Am Coll Cardiol 2000; 35:681-689.

-27 Mann JF, Gerstein HC, Pogue J, Bosch J, Yusuf S: Renal insufficiency as a predictor of cardiovascular outcomes and the impact of ramipril: the HOPE randomized trial. Ann Intern Med 2001;134:629-636.
28 Fried LP, Kronmal RA, Newman AB, Bild DE, Mittelmark MB, Polak JF, Robbins JA, Gardin JM: Risk factors for 5-year mortality in older adults: The Cardiovascular Health Study. JAMA 1998;279:585-592.

29 Manolio TA, Kronmal RA, Burke GL, O’Leary $\mathrm{DH}$, Price TR: Short-term predictors of incident stroke in older adults. The Cardiovascular Health Study. Stroke 1996;27:1479-1486.

30 Wannamethee SG, Shaper AG, Perry IJ: Serum creatinine concentration and risk of cardiovascular disease: A possible marker for increased risk of stroke. Stroke 1997;28: 557-563.

31 Henry RM, Kostense PJ, Bos G, Dekker JM, Nijpels G, Heine RJ, Bouter LM, Stehouwer $\mathrm{CD}$ : Mild renal insufficiency is associated with increased cardiovascular mortality: The Hoorn Study. Kidney Int 2002;62:1402-1407.
32 Garg AX, Clark WF, Haynes RB, House AA: Moderate renal insufficiency and the risk of cardiovascular mortality: Results from the NHANES I. Kidney Int 2002;61:1486-1494.

>33 Beddhu S, Allen-Brady K, Cheung AK, Horne BD, Bair T, Muhlestein JB, Anderson JL: Impact of renal failure on the risk of myocardial infarction and death. Kidney Int 2002;62: 1776-1783.

34 Muntner P, He J, Hamm L, Loria C, Whelton PK: Renal insufficiency and subsequent death resulting from cardiovascular disease in the United States. J Am Soc Nephrol 2002;13: 745-753.

35 Hsu CY, Chertow GM: Chronic renal confusion: insufficiency, failure, dysfunction, or disease. Am J Kidney Dis 2000;36:415-418.

36 Weiner DE, Tighiouart H, Amin MG, Stark PC, MacLeod B, Griffith JL, Salem DN, Levey AS, Sarnak MJ: Chronic kidney disease as a risk factor for cardiovascular disease and allcause mortality: A pooled analysis of community-based studies. J Am Soc Nephrol 2004; 15 : 1307-1315. 